\title{
Development of Space Vector Modulation Control Strategies for Grid Connected Variable Speed Permanent Magnet Synchronous Generator Wind Turbines
}

\author{
Ahmed S. Al-Toma \\ Department of Electronic and \\ Computer Engineering \\ Brunel University London \\ Uxbridge, UB8 3PH, UK
}

Email: (Ahmed.al-toma@brunel.ac.uk)

\author{
Gareth A. Taylor \\ Department of Electronic and \\ Computer Engineering \\ Brunel University London \\ Uxbridge, UB8 3PH, UK \\ Email: (Gareth.Taylor@brunel.ac.uk)
}

\author{
Maysam Abbod \\ Department of Electronic and \\ Computer Engineering \\ Brunel University London \\ Uxbridge, UB8 3PH, UK \\ Email:(Maysam.Abbod@brunel.ac.uk)
}

\begin{abstract}
This paper presents modelling, simulation and analysis of novel control strategies for variable speed wind turbines driven by a Permanent Magnet Synchronous Generators (PMSG) connected to the grid. The machine side controller is designed to match Maximum Power Point Tracking (MPPT) to obtain high extraction of wind power while connected to a the grid, and the grid side controller fixes the DC voltage that is converted to fixed 3-ph AC voltages and frequency. Main strategies of PI control and Model predictive control (MPC) have been discussed and compared to each other. Simulated voltage and current profiles are also presented in the paper in different cases of operation.

Index Terms-Permanent Magnet Synchronous Generator, PI control, Model predictive control.
\end{abstract}

\section{INTRODUCTION}

In recent years, there is a real orientation on production of clean energy, especially wind energy to keep environment within agreeable limit of constraints of noise and pollution. This led to produce wind energy with multiple considerations of control and protection to enhance the power system generation in a good performance of generation quantities such as voltage, frequency and power. To achieve that, wind energy has been controlled during the operation process to keep appropriate amount of power injected to the power grid or stored in batteries. Squirrel-Cage Induction Generators (SCIG) and Double Fed Induction Generators (DFIG) are typically used in fixed speed systems.

Generally fixed speed turbines are well-established, simple, robust, reliable, cheaper compared to those generators that used in variable speed Wind Energy Conversion System (WECS). Due to continuous variation of speed of wind during short period of time, the need of variable speed generators becomes necessary. On the other hand, Permanent Magnet Synchronous Generators (PMSG) are most recently deployed in generation of electrical power from the wind energy either in stand-alone operation or grid connection due to higher power density, higher efficiency, and good power capability besides low maintenance due to less mechanical components [1] [2].

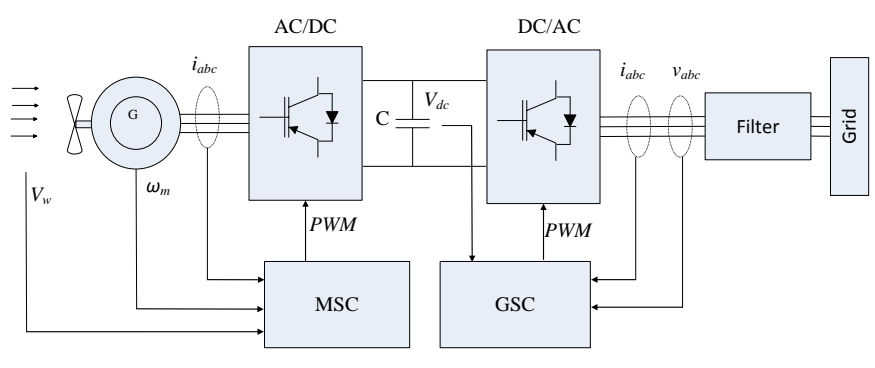

Fig. 1. Schematic diagram of WECS model

The schematic diagram of the system is shown in fig(1). The proposed model of this paper shows that the combination of Wind Turbine (WT) directly driven a PMSG connected to the Grid to satisfy the grid code requirements of constant Voltage and frequency. For the grid connection design, the control circuit is necessary to maintain the electrical voltage and frequency within rated limit in case of wind speed variation. Field Oriented Control (FOC) as Direct Torque Control (DTC) are both dominate the theoretical and practical simulation and application of Machine Sid Converter (MSC)control. [3] For grid side control (GSC), voltage oriented control (VOC) and direct power control (DPC) are two Familiar strategies are used to control the output signals of currents. As well as the wind speed is variable, the extracted power of the wind should be maximum to achieve the highest values of efficiencies for all cases of the wind speed. [4]

Nowadays, different types of controllers are developed and enhanced the wind system to get several advantages such as performance, reduction in system losses, familiarity with computer system and reduction in size and cost. Model predictive control (MPC) is one of these widely expanded control equipments that demonstrate good robustness and 
performance. [5] [6]

This paper presents analysis and design of (FOC) schemes of generator side and (VOC) schemes to grid side to satisfy the mathematical system model to predict the future behaviour during each sampling period [7].

\section{System Modelling}

\section{A. Wind Turbine Model}

Wind energy is transferred to mechanical power through wind turbine and hence to the electric energy through generator. The kinetic energy in a flow of air through a unit area perpendicular to the wind direction per mass is converted to mechanical energy. From Newtons Law, the power captured by the wind turbine for an air stream flowing through an area $\boldsymbol{A}$, and then generated by the wind is equal to:

$$
P_{m}=\frac{1}{2} \rho A C_{p} v_{w}^{3}
$$

where $P_{m}$ is the wind power (watts or $\mathrm{J} / \mathrm{s}$ ),$\rho$ is the air density of values $1.11 .3(\mathrm{~kg} / \mathrm{m} 3), A$ is the area swept out by turbine blades $\left(m^{2}\right), \mathrm{V}$ is the wind speed $(\mathrm{m} / \mathrm{s})$. The power coefficient $C_{p}$ can be expressed as a function of the tip speed ratio (TSR) $\lambda$ and pitch angle $\beta$ by :

$$
C_{p}=\frac{\omega_{m} \cdot R}{v}
$$

where $\beta$ is the pitch angle of the blade in degrees, $\mathbf{R}$ is the radius of the area swept out by blades turbine and $\omega_{m}$ is the mechanical speed of the generator in $\mathrm{rad} / \mathrm{s}$. The power coefficient can be expressed in (3):

$$
C_{p}(\lambda, \beta)=C_{1}\left(\frac{C_{2}}{\gamma}-C_{3} \beta-C_{4}\right) e^{\frac{-C_{5}}{\gamma}}+C_{6} \lambda
$$

and

$$
\gamma=\frac{1}{(\lambda+0.08 \beta)-\left(0.035 \beta^{2}+1\right)}
$$

The coefficients parameters of (3) are imperical constants and be estimated for the WT as: $\mathrm{C} 1=0.5176, \mathrm{C} 2=116, \mathrm{C} 3=$ $0.4, \mathrm{C} 4=5, \mathrm{C} 5=21$, and C6 $=0.0068$ In Practice, the power coefficient $C_{p}$ reaches a maximum value will be within the range 40-50 percent according to Betz 's limit. This means that the power extracted from the wind is always less than 50 percent.

This value below the theoretical limit is caused by the inefficiencies and then leads to a various aerodynamic losses which depend on the rotor construction (number and shape of blades, weight, stiffness, etc.).

The relationship of the performance power coefficient, $C_{p}$ of a wind turbine and the tip speed ratio (TSR) shows that the maximum values of $C_{p}$ in all operation condition happen at an optimum values of (TSR). By adjusting these values in the control circuit to get the Maximum Power Point Tracking (MPPT) for any variation of wind speed.Fig(2) shows the relationship between the power coefficient $C_{p}$ and optimum values of (TSR)for different values of pitch angle $\beta$. The output mechanical power is changed with the angular velocity $\omega$, for variable values of the wind speed according to the

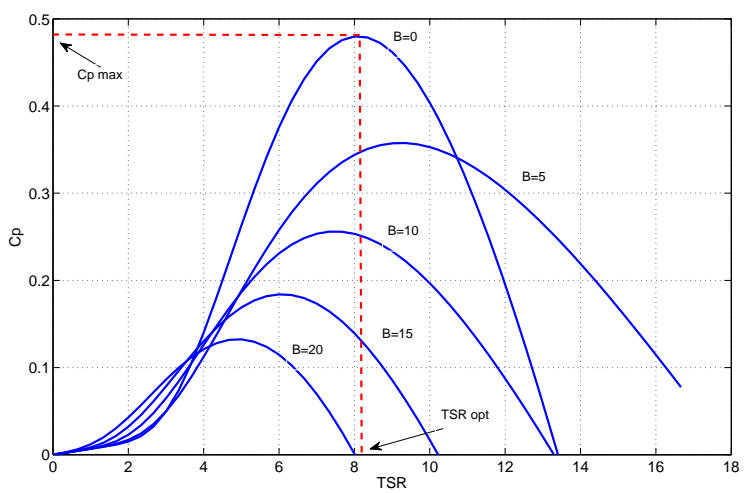

Fig. 2. Variation of Power cofficient with TSR

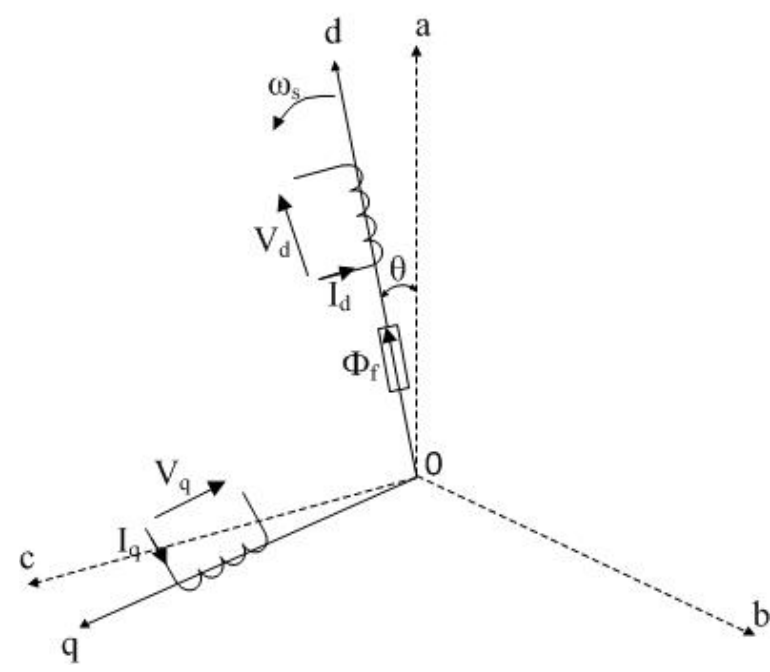

Fig. 3. abc-dq axis.

synchronous machine characteristics. As a significant aim of this study to achieve the optimum values of $\omega$, that satisfy the maximum output mechanical power of the wind. Therefore the above important relationships of $C_{p}$ and $\lambda$ should be taken in to account to get optimum design as shown in Fig. 4. The dynamic equation of the wind turbine is given in(9):

$$
J \frac{d \omega_{m}}{d t}=T_{e}-T_{m}-F \omega_{m}
$$

where $J$ is the total moment of inertia, $F$ is the viscous friction coefficient and $T_{m}$ is the mechanical torque developed by the turbine.

\section{B. PMSG Model}

The output voltages of PMSG can be represented in synchronous rotating reference frame where the q-axis is 90 degrees ahead of the d-axis with respect to the direction of 
rotation. The d-q stator voltages equations of this generator are given by (5) and (6) respectively.

$$
\begin{gathered}
v_{d}=R_{d} i_{d}+L_{d} \frac{d i_{d}}{d t}-\omega_{e} L_{q} i_{q} \\
v_{q}=R_{q} i_{q}+L_{q} \frac{d i_{q}}{d t}+\omega_{e}\left(L_{d} i_{d}+\psi_{f}\right)
\end{gathered}
$$

where $L_{d}$ and $L_{q}$ are the inductances of the generator on the $d$ and $q$ axis, $R_{g}$ is the stator resistance, $\psi_{f}$ is the permanent magnetic flux and $\omega_{e}$ is the electrical rotating speed of the PMSG defined:

$$
\omega_{e}=p_{n} \omega_{m}
$$

where $p_{n}$ is the number of pole pairs.

For $p$ number of pole pairs in the machine, the electromagnetic torque can be expressed as :

$$
T_{e}=\frac{3}{2} p_{n} \omega_{e}\left(\left(L_{d}-L_{q} i_{d} i_{q}\right)+\psi_{m} i_{q}\right)
$$

By controlling the value of $i_{q}$, electromagnetic torque can be controlled. The values of this torque is followed the mechanical torque and then mechanical power which satisfy MPPT.

\section{CONTROL SCHEMES OF THE SYSTEM}

\section{A. TRADITIONAL CONTROL SCHEMES}

Since all quantities have to be kept within acceptable limit the output voltage and frequency have to be constant.Then the control system has been designed to perform this aim in both machine side and load side to satisfy this aim .

One of the famous control scheme is vector control which use field oriented control (FOC) to achieve an acceptable limit of accuracy and speed. This type of control uses a Proportional Integral (PI) Controller to adjust the error of signals.

In Machine side control circuit, there are two loops that perform this scheme, inner loop and outer loop. The aim of inner loop is to control the d-axis and q-axis currents while the outer loop to control the generator speed. The outer loop controls the speed of the generator with the set value that satisfy the condition of Maximum Power Point Tracking of the wind. This controller has a proportional parameter $K_{p}$ and integrator parameter $K_{I}$, which have to be tuned in a proper way to get the optimum operation and response. The commanded d-reference current $i_{q}$ ref is determined by speed controller and the output of PI controller is:

$$
i_{q} r e f=K_{p} \omega+K_{I} \omega \int e_{\omega} d t
$$

where $K_{p}$ and $\mathrm{KI}$ are the proportional and integral parameters of PI controller, while $e_{\omega}$ is the error between the reference speed and measured speed of generator.

According to $\mathrm{q}$-axis reference current, the $\mathrm{d}-\mathrm{q}$, the controlled voltages of the inner loop can be determined by two the PI controllers as shown in the following equations:

$$
\begin{gathered}
V_{d}^{*}=K_{p i} e_{d}+K_{I i} \int e_{d} d t-\omega_{r} L_{q} i_{q} \\
V_{q}^{*}=K_{p i} e_{q}+K_{I i} \int e_{q} d t+\omega_{r}\left(L_{d} i_{d}+\phi_{m}\right)
\end{gathered}
$$

where, $V_{d}^{*}, V_{q}^{*}$ are the reference voltages of $d-q$ axis voltages, and $K_{p i}$ and $K_{I i}$ are the a proportional and integral parameters gain of the current loop PI controller respectively, while $e_{d}$ and $e_{q}$ are the error of $d-q$ current component as shown in (13), and (14) respectively :

$$
\begin{aligned}
& e_{d}=i_{\text {dref }}-i_{d} \\
& e_{q}=i_{\text {qref }}-i_{q}
\end{aligned}
$$

Finally, the controlled voltages will be transferred to $a b c$ voltages by Park inverse transformation to get the values of switches of IGBT.

In the Grid side control (GSC) circuit, there are also two loops that perform this scheme, inner loop and outer loop. In Outer loop control DC voltage should be adjusted to follow the set values.

\section{B. MODEL PREDICTIVE CONTROL SCHEMES}

As the manufacturing and wind energy market have been developed recently, the relevant modern and robust controllers become more and more in need to follow the grid code requirements and enforces the engineering issues.

One of the recent type of developed model is Model Predictive Control (MPC) introduced as an alternative controller which has a fast grow in power system industry due to several advantages. [8]- [9]

\section{ANALYSIS OF MODEL PREDICTIVE CONTROL}

\section{A. MACHINE SIDE CONTROL}

The predictive control of machine side is shown in fig 4. The cascaded control loop has been used to control currents and speed of the machine. This can be divided to internal loop for currents and external loop for speed. The external speed loop can be controlled by traditional PI control to adjust the value of rotor speed.

On the other hand, an (MPC)internal control loop controls the stator currents in the $d q$ synchronous reference frame.

Maximum torque at the minimum current can be obtained by adjusting $\mathrm{d}$ axis stator current reference $i_{s d}^{*}$ to zero. The other current of the $\mathrm{q}$ axis stator current reference $i_{s q}^{*}$ is computed via the external speed controller.

1) Current Loop Control: In Order to control the $d q$ axis currents, the generator equations (6) and (7) can be re- written as :

$$
\frac{d i_{s d}}{d t}=\frac{1}{L_{s d}}\left(V_{s d}-R_{s} i_{s d}+\omega_{d q} L_{s q} i_{s q}\right)
$$




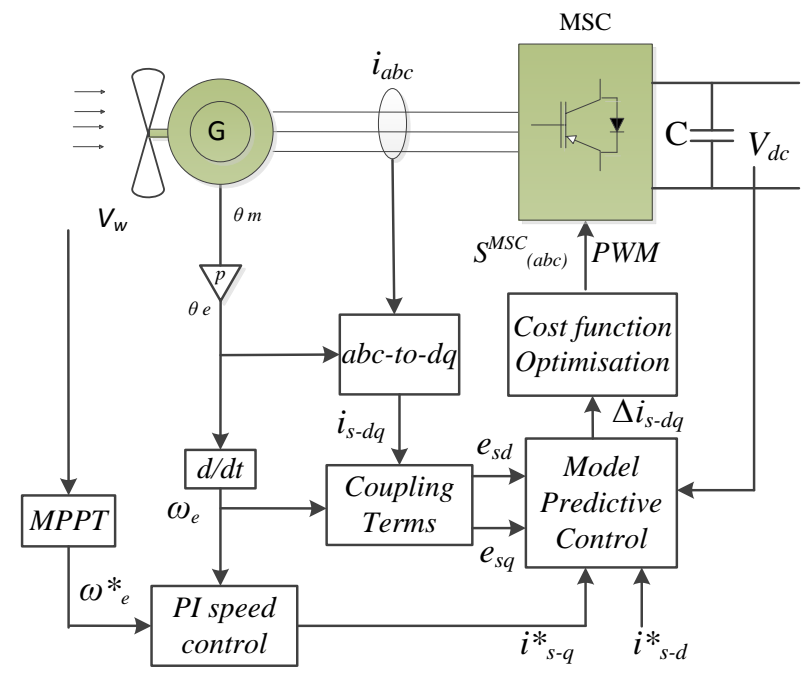

Fig. 4. MPC - MSC Sckematic Diagram for the Machine Side

$$
\frac{d i_{s q}}{d t}=\frac{1}{L_{s q}}\left(V_{s q}-R_{s} i_{s q}-\omega_{d q} L_{s q} i_{s d}+\omega_{d q} p s i_{f}\right)
$$

In order to get a predictive values of currents, the above equations (15) and (16) can be represented using Euler discretization method as follow:

$$
\begin{gathered}
i_{s d}[k+1]=\frac{T_{s}}{L_{s d}}\left(V_{s d}[k]-e_{s d}[k]\right)+\left(1-\frac{T_{s}}{T_{s d}}\right) i_{s d}[k] \\
i_{s q}[k+1]=\frac{T_{s}}{L_{s q}}\left(V_{s q}[k]-e_{s q}[k]\right)+\left(1-\frac{T_{s}}{T_{s q}}\right) i_{s q}[k] \\
e_{s d}[k]=-L_{s q} \omega_{d q}[k] i_{s q}[k] \\
e_{s q}[k]=L_{s d} \omega_{d q}[k] i_{s d}[k]+\omega_{d q}[k] \phi_{r d}[k]
\end{gathered}
$$

where $T s$ is the sampling period. $i_{s d}[k+1]$ and $i_{s q}[k+1]$ are the predicted predicted $\mathrm{d}$ and $\mathrm{q}$ stator current components at the $(k+1)$ th sampling period. $i_{s d}[k]$ and $i_{s q}[k]$ are measured $d$ and $q$ stator current components during $k$ th sampling period. $T_{s d}=L_{s d} / R_{s}$ and $T_{s q}=L_{s q} / R_{s}$ are time constant of $d$ and $q$ circuit respectively. The $e_{s d}$ and $e_{s q}$ terms refer respectively to the $d$ and $q$ coupling terms.

The evolution of the $d$ and $q$ stator current components depends upon the applied stator voltage components $V_{s d}^{j}[k]$ and $V_{s q}^{j}[k]$ at the $k$ th sampling period.

The values of these voltage components can be expressed in the $d q$ synchronous reference frame and can be determined through the rotation angle equal to $\left(\theta_{d q}\right)$ to the $\alpha \beta$ components of the stator voltage vectors as shown in table I. Taking in to account the eight switching states combinations of the
TABLE I

MSC SWITCHING STATES AND CORRESPONDING OUTPUT VOLTAGES

\begin{tabular}{|c|c|c|c|c|c|c|}
\hline $\mathbf{S a}$ & $\mathbf{S b}$ & $\mathbf{S c}$ & $\mathbf{V}_{j}^{\alpha}$ & $\mathbf{V}_{j}^{\beta}$ & $\mathbf{V}_{j}$ & $\mathbf{V}_{d q}^{j}$ \\
\hline 0 & 0 & 0 & 0 & 0 & $V_{0}$ & $V_{d q}^{0}$ \\
\hline 1 & 0 & 0 & $2 V_{d c} / 3$ & 0 & $V_{1}$ & $V_{d q}^{1}$ \\
\hline 1 & 1 & 0 & $V_{d c} / 3$ & $V d c / \sqrt{3}$ & $V_{2}$ & $V_{d q}^{2}$ \\
\hline 0 & 1 & 0 & $-V_{d c} / 3$ & $V d c / \sqrt{3}$ & $V_{3}$ & $V_{d q}^{3}$ \\
\hline 0 & 1 & 1 & $-2 V_{d c} / 3$ & 0 & $V_{4}$ & $V_{d q}^{4}$ \\
\hline 0 & 0 & 1 & $-V_{d c} / 3$ & $-V d c / \sqrt{3}$ & $V_{5}$ & $V_{d q}^{5}$ \\
\hline 1 & 0 & 1 & $V_{d c} / 3$ & $-V d c / \sqrt{3}$ & $V_{6}$ & $V_{d q}^{6}$ \\
\hline 1 & 1 & 1 & 0 & 0 & $V_{7}$ & $V_{d q}^{7}$ \\
\hline
\end{tabular}

MSC with two combinations $V_{0}$ and $V_{7}$ that lead to null stator voltage vector, the equations (17) and (18) can be represented for the different possibilities of the $d$ and $q$ stator voltage components Space vector modulation.

Then, it is able to predict the values of $d q$ stator vector components $\left(\Delta i_{s d}^{j}[k+1]\right)$ and $\left(\Delta i_{s q}^{j}[k+1]\right)$ for all values of $(j=0 \ldots 7)$. The current errors are defined as the difference between the reference stator currents vectors $i_{s d}^{*}[k], i_{s q}^{*}[k]$ during the $k$ th sampling period of time and the predicted one at the $(k+1)$ th sampling period of time. These errors can be expressed as :

$$
\begin{aligned}
\Delta i_{s d}^{j}[k+1] & =i_{s d}^{*}[k]-i_{s d}^{j}[k+1] \\
\Delta i_{s q}^{j}[k+1] & =i_{s q}^{*}[k]-i_{s q}^{j}[k+1]
\end{aligned}
$$

The errors estimated for all sectors values of $(j=0 \ldots 7)$.

According to the above equations (17), (18), (21) and (22), a cost function $g^{j}$ is applied to the obtained stator current error components. This cost function can be defined as in (23)

$$
g^{j}=\left|\Delta i_{s d}^{j}[k+1]\right|+\left|\Delta i_{s q}^{j}[k+1]\right|
$$

Finally, the selection of the optimal switching states combination $S(a, b, c)^{o p t}$ can be obtained that leads to the minimal cost function $\operatorname{Min}\left(g^{j}\right)$ for all values of $j=0 \ldots 7$.

2) Speed control loop: PI controller (with proportional gain $K_{p \omega}$ and integral gain $K_{i \omega}$ )can be used in speed control. The block diagram of the outer loop of speed controller has been built as a traditional PI control system. By neglecting the effect of the load torque $T_{L}$, the transfer function of the speed control loop can be expressed as follows [10] in (24) :

$$
\frac{\omega}{\omega^{*}}=\frac{1}{1+\frac{J}{p K_{p \omega}} s}=\frac{1}{1+T_{\omega} s}
$$

The achieved transfer function has the form of a first order system characterized by a time constant $T \omega$ equal to $J / p K_{p \omega}$. Determination of the PI speed controller gains, depends upon the values of poles and zeros of the equation of the transfer function. we put the value of time constant $T \omega$ in the equation, then the proportional gain $K_{p \omega}$ and integral gain $K_{i \omega}$ can be expressed as follows:

$$
K_{p \omega}=\frac{J}{p T_{w}}
$$




$$
K_{i \omega}=\frac{f K_{p \omega}}{J}
$$

\section{B. GRID SIDE CONTROL}

The MPC for the grid side is shown in Fig. 5. A cascade control loops have been used, and a PI controller controls the dc-link voltage $\mathrm{Vdc}$ in external loop. The main internal control loop an MPC-based controls grid currents in the dq synchronous reference frame, where the $\mathrm{d}$ axis is linked to the grid voltage vector. The $q$ axis grid current reference $i_{g q}^{*}$ is set to zero in order to impose a unit power factor operation, whereas the $d$ axis grid current reference $i_{g d}^{*}$ is computed by the PI controller of the outer dc-link voltage control loop.

Considering that the main objective of the MPC algorithm is to control the active and reactive power through the control of the $d$ and $q$ grid current components.

1) Current Control Loop: In the same manner that used in Machine Side Control (MSC), the current can be controlled by by adjusting the predicted vales of $d$ and $q$ grid current components.

During each sampling period, the evolution of the $\mathrm{d}$ and $\mathrm{q}$ grid current components depends on the applied converter voltage components $V_{\text {conv }_{d}}[k]$ and $V_{\text {conv }_{q}}[k]$ at the $k^{\text {th }}$ sampling period.

It is obvious that the voltage vectors $V_{\text {conv }_{d}}[k]$ and $V_{\text {conv }}[k]$ depend also on the dc-link voltage Vdc level using Park and Clark transformation as in the following equations:

$\left[\begin{array}{c}V_{\text {con-d }}^{j}[k] \\ V_{\text {con-q }}^{j}[k]\end{array}\right]=\left[\begin{array}{cc}\cos \left(\theta_{d q}[k]\right. & \sin \left(\theta_{d q}[k]\right. \\ -\sin \left(\theta_{d q}[k]\right. & \cos \left(\theta_{d q}[k]\right.\end{array}\right]\left[\begin{array}{c}V_{c o n-\alpha}^{j}[k] \\ V_{c o n-\beta}^{j}[k\end{array}\right]$

$$
\left[\begin{array}{c}
V_{c o n-\alpha}^{j}[k] \\
V_{c o n-\beta}^{j}[k]
\end{array}\right]=\frac{2}{3} V_{d c}^{*}\left[\begin{array}{ccc}
1 & -\frac{1}{2} & -\frac{1}{2} \\
0 & \frac{\sqrt{3}}{2} & -\frac{\sqrt{3}}{2}
\end{array}\right]\left[\begin{array}{c}
S_{i a}[k] \\
S_{i b}[k] \\
S_{i c}[k]
\end{array}\right]
$$

were $V_{c o n-d}^{j}[k]$ and $V_{c o n-q}^{j}[k]$ are voltage vectors of $d$ and $q$ axis component, and $V_{c o n-\alpha}^{j}[k], V_{c o n-\beta}^{j}[k]$ are the output converter voltage vectors in the stationary values of $\alpha$ and $\beta$ axis, and $S_{i a}[k], S_{i b}[k], S_{i c}[k]$ are the switching signals of the controller.

Finally,in the same manner the cost function can be defined in equation:

$$
g^{j}=\left|\Delta i_{g d}^{j}[k+1]\right|+\left|\Delta i_{g q}^{j}[k+1]\right|
$$

Minimisation of the cost function can be achieved by selection the optimal values of the above switching signals considering that the applied switching signals during the previous sampling period so that the switching frequency is minimised.

2) DC voltage Control Loop: The DC link voltage equation as shown in fig. can be expressed as a function of the voltage across the capacitor as in (30):

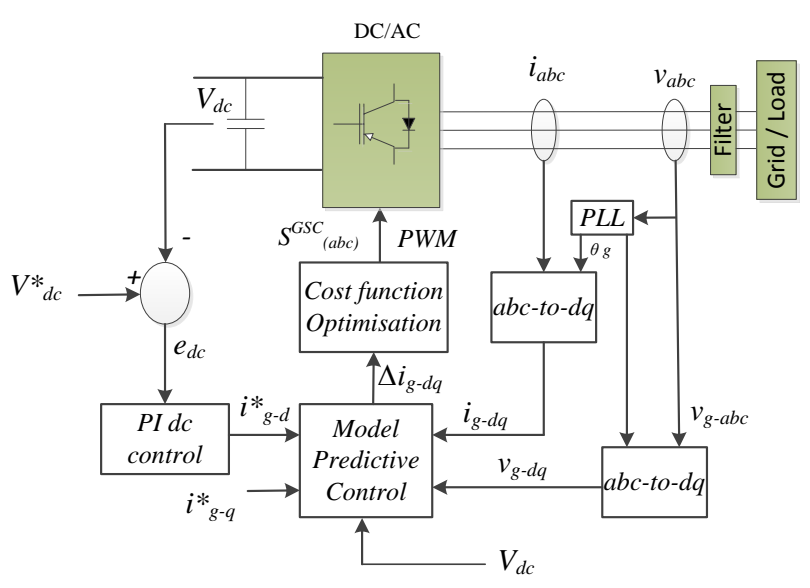

Fig. 5. MPC - GSC for the Grid Side

$$
V_{d c}=\frac{1}{C s} i_{c}=\frac{1}{C s}\left(i_{d c}-i_{i n v}\right.
$$

Where $i_{c}$ is the capacitor current and $C$ is the dc-link capacitor, $i_{d c}$ is the current at the output of Grid Side Control and $i_{i n v}$ is the current at the input of the Grid side. By cancelling $i_{i n v}$ effect, the transfer function of dc-link voltage control loop is given in (31):

$$
\frac{V_{d c}}{V_{d c}^{*}}=\frac{\frac{K_{p d c}}{C} s+\frac{K_{i d c}}{C}}{s^{2}+\frac{K_{p d c}}{C} s+\frac{K_{i d c}}{C}}
$$

By using a second order system characterized by a natural frequency of oscillation equal to $\omega_{n d c}$ a damping ratio $\zeta_{d c}$, the tuned parameters can be obtained as in (32) and (33) :

$$
\begin{gathered}
K_{p d c}=2 C \zeta_{d c} \omega_{n d c} \\
K_{i d c}=C \omega_{n d c}^{2}
\end{gathered}
$$

\section{Simulation and Results}

Using Matlab/Simulink environment tool to show the effect of the novel control of (MPC) in (MSC) and (GSC) respectively. The simulation shows that the effect of the controller during different values of wind speed. Some initial condition of simulation should be taken in to account to operate the system fairly. In (MSC) the set value of $i_{d}$ is equal to zero to achieve Maximum torque at the minimum current. The dclink capacitor should be charged to rated value of de voltage ( $\mathrm{Vdc}=7100)$. In (GSC) the set value of $i_{q}$ is equal to zero to ensure a unity power factor. Fig (6) shows the variation of wind speed with respect to time. As a result to this variation, the generator speed will be varied when the wind speed change, then the output generator current also be changed as shown in fig (7). The DC link voltage will be imposed to be constant 


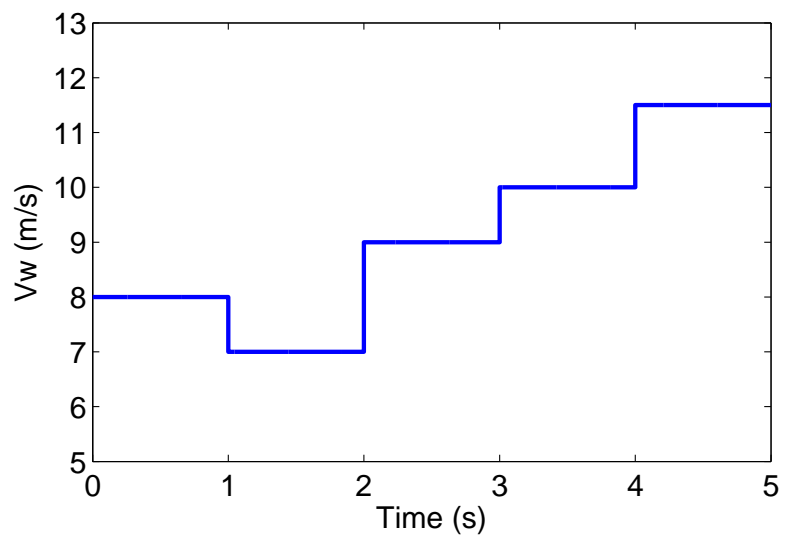

Fig. 6. Variation of Wind Speed

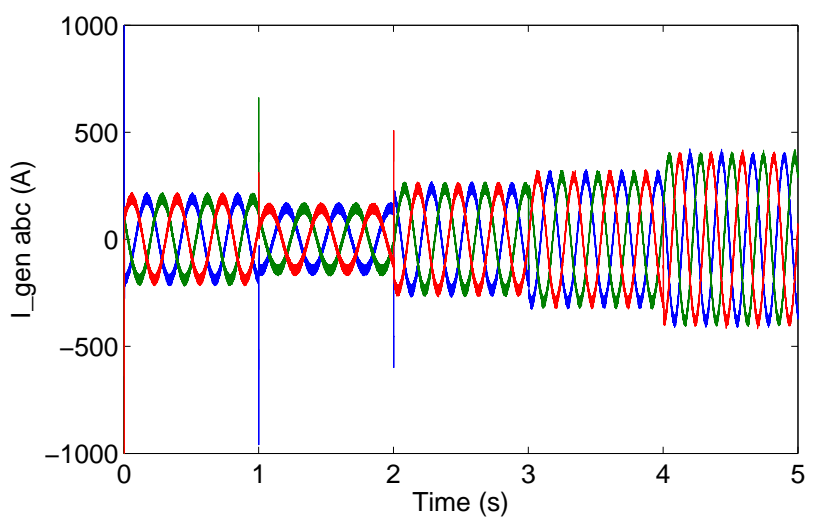

Fig. 7. Variation of the generator currents

by the (GSC)as shown in fig( ),then output grid voltage will be fixed as shown in fig ().

\section{CONCLUSION}

A Space Vector Pulse Width Modulation (SVPWM) control has been used with a Model based Predictive Control (MPC) for a back-to-back converter in wind energy system. This control has been used to the well known Field Oriented Control (FOC) with grid connection.It is divided into two part: Machine Side Control (MSC) and Grid SIDE Control (GSC). The first one is adjust the rotor speed to achieve (MPPT) to get high efficiency in power conversion while the second one control the the DC-Link voltage to adjust the grid voltage as well. The developed (MPC) shows that it has controller is robust performance to wind variation as shown above.

\section{REFERENCES}

[1] M. Liserre, R. Cardenas, M. Molinas, and J. Rodriguez, "Overview of multi-mw wind turbines and wind parks," IEEE Transactions on Industrial Electronics, vol. 4, no. 58, pp. 1081-1095, 2011.

[2] A. Hansen, F. Iov, and . H. L. H. Blaabjerg, Frede, "Review of contemporary wind turbine concepts and their market," Wind Engineering, vol. 3 , no. 28 , pp. 247-263, 2004.

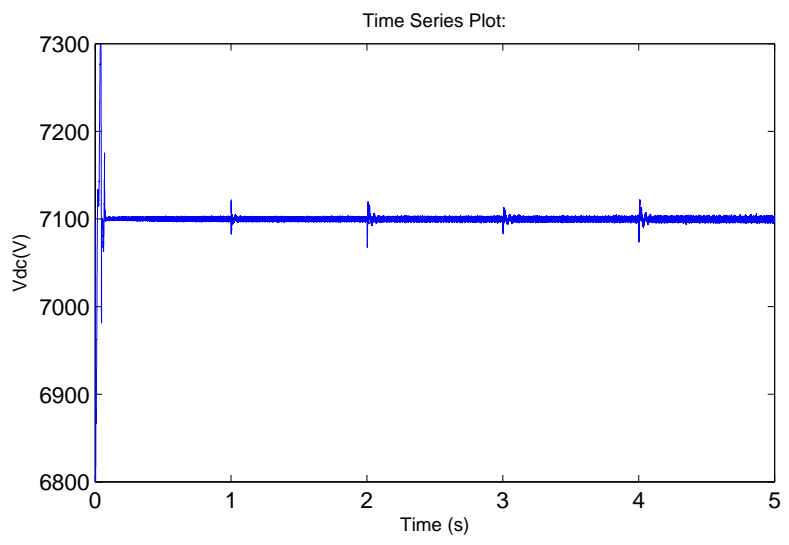

Fig. 8. Variation of Dc Link Voltage

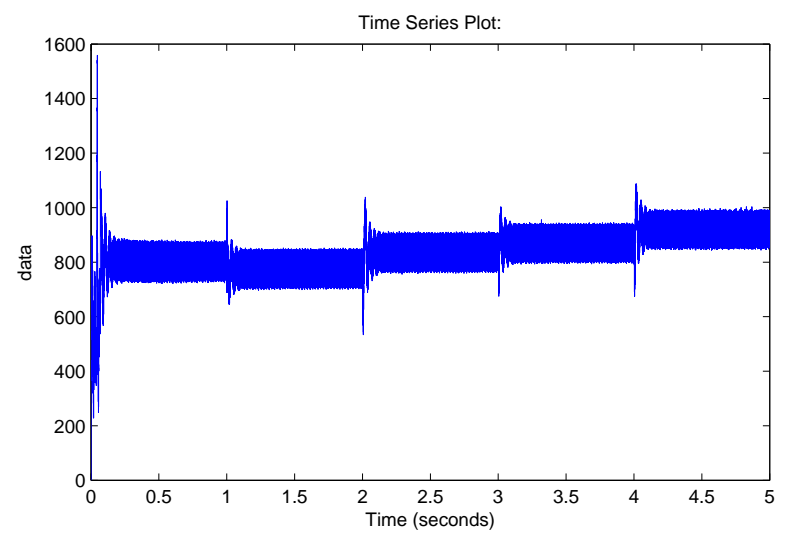

Fig. 9. Variation of Output Current (rms)

[3] M. Chinchilla, S. Arnaltes, and J. C. Burgos, "Control of permanentmagnet generators applied to variable-speed wind-energy systems connected to the grid," Energy Conversion, IEEE Transactions on, vol. 21, no. 1, pp. 130-135, 2006.

[4] A. S. Al-Toma, G. A. Taylor, and M. Abbod, "Modelling and simulation of load connected fixed blade wind turbine with permanent magnet synchronous generators," in Power Engineering Conference (UPEC), 2015 50th International Universities. IEEE, 2015, pp. 1-6.

[5] S. Kouro, P. Cortés, R. Vargas, U. Ammann, and J. Rodríguez, "Model predictive controla simple and powerful method to control power converters," Industrial Electronics, IEEE Transactions on, vol. 56, no. 6, pp. 1826-1838, 2009.

[6] P. KaraMaNaKOS, T. Geyer, N. Oikonomou, F. D. KIEFErNDOrF, and S. MaNIaS, "Direct model predictive control: A review of strategies that achieve long prediction intervals for power electronics," Industrial Electronics Magazine, IEEE, vol. 8, no. 1, pp. 32-43, 2014.

[7] R. O. Ramirez, J. R. Espinoza, P. E. Melin, M. E. Reyes, E. E. Espinosa, C. Silva, and E. Maurelia, "Predictive controller for a threephase/single-phase voltage source converter cell," Industrial Informatics, IEEE Transactions on, vol. 10, no. 3, pp. 1878-1889, 2014.

[8] A. Linder, R. Kanchan, R. Kennel, and P. Stolze, Model-based predictive control of electric drives. Cuvillier, 2010.

[9] P. Cortés, M. P. Kazmierkowski, R. M. Kennel, D. E. Quevedo, and J. Rodríguez, "Predictive control in power electronics and drives," Industrial Electronics, IEEE Transactions on, vol. 55, no. 12, pp. 43124324, 2008.

[10] I. Maaoui-Ben Hassine, M. Naouar, and N. Mrabet-Bellaaj, "Model based predictive control strategies for wind turbine system based on pmsg," in Renewable Energy Congress (IREC), 2015 6th International. IEEE, 2015, pp. 1-6. 